\title{
Feasibility Evaluation of Cu-Nb Microcomposite Joints Formed by Magnetic Field Pressing for Pulsed Power Applications
}

\author{
Nikolaj VIŠNIAKOV, Gediminas MIKALAUSKAS, Raimonda LUKAUSKAITĖ, Jelena ŠKAMAT, Olegas ČERNAŠĖJUS, Vitalij NOVICKIJ
}

\begin{abstract}
In this work we have evaluated the feasibility of the magnetic field pressing technology for formation of Cu-Nb joints for further pulsed power applications. The electrical and mechanical properties of joints have been investigated. The structure of $\mathrm{Cu}-\mathrm{Nb}$ conductors joints was investigated using optical and scanning electron microscopy. The mechanical characteristics have been evaluated using tensile tests. It has been determined that the maximum tensile strength of 350 MPa could be achieved, which is $30,4 \%$ of a Cu-Nb wire strength. The applied pressing technology allowed minimizing the defects in the microcomposite structure due to solid-state joining process, however the resultant decrease of conductivity by $10 \%$ influenced an increase of the Joule heating. After a 2 min $200 \mathrm{~A}$ current flow the difference of $54,4{ }^{\circ} \mathrm{C}$ between the conductor and the joint area was observed. It was concluded that the $\mathrm{Cu}-\mathrm{Nb}$ joints formed by magnetic field pressing are applicable for pulsed magnet setups where non-destructive joints are required.
\end{abstract}

Keywords: Cu-Nb wire; composite materials; electrical cables; electrical contact connection

\section{INTRODUCTION}

In the past decades the applications of pulsed magnetic fields and pulsed power technology expanded significantly, covering the scientific areas of material science, optics, biotechnology and many other, which created a need for development of flexible, compact and energy-efficient pulsed power setups. Nevertheless, the generation of high magnetic fields $(>20 \mathrm{~T})$ is still challenging, due to the requirement of high currents in the range of tens of $\mathrm{kA}$. As a result, the majority of systems, which operate in the 20-90 $\mathrm{T}$ range, are complex and stationary, not available commercially, and thus, the access of researchers to high magnetic field infrastructure is limited. One of the most problematic parts of the pulsed high magnetic field generation setup is the magnetic field inductor (coil), which as a rule, resembles a multilayer cylindrical structure (solenoid), consisting from several to hundreds of conducting windings [1]. The high current flow in the windings induces high magnetic field inside the inner volume of the multilayer solenoid, however due to the Lorentz forces, Joule heating and high voltage, there is a high possibility of deformation, winding rupture and voltage breakdown, following by a fault or even explosion, thus the high power inductors (operating in the 20-90 T range) are limited by the amount of the pulses that can be generated. Therefore, the conductors that are used for winding of solenoids should exhibit high tensile strength and conductivity, at the same time should be flexible and resistant to repetitive deformation. At the current state four types of composite conductors are typically used: $\mathrm{Cu}-\mathrm{Nb}$ and $\mathrm{Cu}-\mathrm{Ag}$ micro-composites, GlidCop and the CuSS macro-composites [2-4]. The $\mathrm{Cu}-\mathrm{Nb}$ micro-composite is currently one of the best due to high tensile strength (Rm) 1100-1500 MPa, yield strength (Rp) $850 \mathrm{MPa}$ and relatively high conductivity of $67-70 \%$ IACS [5]. These materials are also used for production of high power electrical transformers for power plants, high-voltage lines, strong electromagnets for magnetic levitation transport systems, equipment for plastic deformation by magnetic field, induction welding and other pulsed power machines. During development of high magnetic field inductors or other pulsed power equipment, there is a need to provide conductive connections between separate modules, thus formation of joints is required $[6,7,8]$. At the same time the joint becomes a weak point in the design, since high mechanical, electrical and reliability characteristics should be maintained, which is not always possible. The pulsed magnetic field inductors, transformers or isolated high power conductor structures require very reliable joints due to extension and bending limitations. This problem is still poorly addressed due to the significant decrease in reliability and other technical parameters of a joint, making the electrical connections in pulsed multilayer inductors one the weakest points of the structure, limiting the joint technology mostly to disassemblable solutions [9, 10].

Even though the welding and pressing methods are considered as one of the most progressive, the complexity of joint formation is highly influenced by the composite conductor's structure and processing specifics. In the case of $\mathrm{Cu}-\mathrm{Nb}$ microcomposites the structure consists of copper matrix with integrated thin niobium fibres. The $\mathrm{Nb}$ fibres strengthen the copper matrix, improving the mechanical characteristics, without negative influence on conductivity [5]. The microcomposite conductor manufacturing process is similar to diffusion or pressure welding. The $\mathrm{Cu}-\mathrm{Nb}$ composite wire is formed by mechanical machining pressure during the plastic deformation of materials [11, 12]. Therefore, most of the traditional fusion welding methods are unsuitable for composite materials due to the matrix melting taking place, following by irreversible structural changes [8]. In theory, this problem could be solved using pressing and solid-state welding technologies [13]. For pressed joints formation the conventional mechanical pressing method could be used, while pulsed power methods are also available, e.g. pressing with high power pulsed magnetic field, electro-hydraulic pressing or explosive pressing. However, the pressing with pulsed magnetic field method offers high deformation velocity (up to $20 \mathrm{~s}^{-1}$ ), which allows to reduce the traction force, localize the deformation area and minimize the number of pressing defects. Therefore, in this work we have evaluated the feasibility of the magnetic field pressing technology for formation of $\mathrm{Cu}-\mathrm{Nb}$ joints by analysis of the electrical and 
mechanical characteristics, including the effect of Joule heating, which is particularly relevant for high pulsed power applications.

\section{METHODS AND EXPERIMENTAL}

As an object of the research the $2,4 \times 4,2 \mathrm{~mm} \mathrm{Cu}-\mathrm{Nb}$ microcomposite wire, formed by "assembly-deformation" method has been used. Mechanical properties of this $\mathrm{Cu}$ $\mathrm{Nb}$ wire: $\mathrm{Rp}$ is $830-850 \mathrm{MPa}, \mathrm{Rm}-1120 \mathrm{MPa}$ [14]. Microcomposite structure is made from $\mathrm{Nb}$ fibre $<15 \mathrm{~nm}$ and a copper matrix [11].

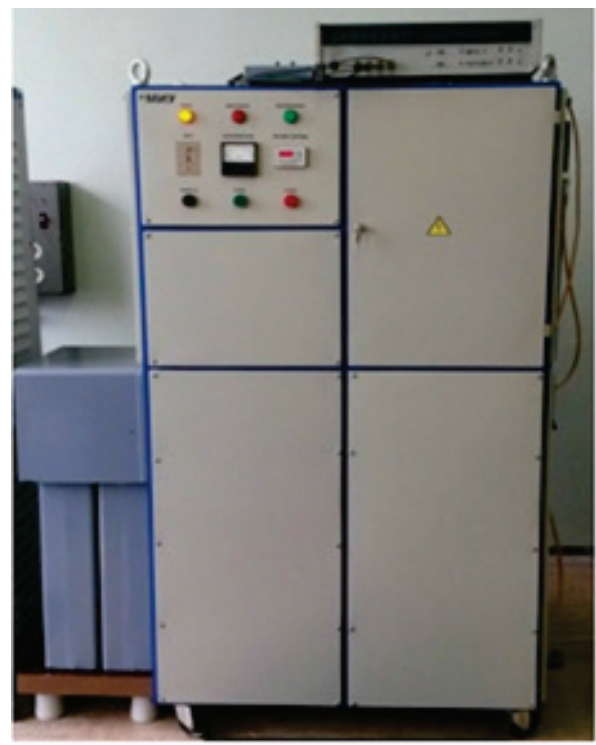

Figure 1 View of experimental pulsed system

Table 1 Characteristics of pulsed magnet system

\begin{tabular}{|c|c|}
\hline Parameter & Value \\
\hline Maximum stored energy/ kJ & 6,8 \\
\hline Maximum impulse energy/ kJ & 6,8 \\
\hline Maximum charging power/ kW & 5,5 \\
\hline Charging capacity/ $\mu \mathrm{F}$ & 450 \\
\hline Average output power of charging device/ VA & 500 \\
\hline Apparent power/ VA & 3000 \\
\hline Single-phase voltage/ V & 220 \\
\hline Number of pulses/min & 2 \\
\hline
\end{tabular}

The magnetic pressing of the $\mathrm{Cu}-\mathrm{Nb}$ has been performed using an experimental pulsed power setup (Fig. 1), which consisted of high voltage $(5,5 \mathrm{kV})$ pulsed power $(6,8 \mathrm{~kJ})$ discharge unit and the inductor for the sample (Physical Technical Institute, National Academy of Sciences of Belarus). The summary of the setup parameters is presented in Tab. 1. The capacitor of the pulsed power setup $(450 \mu \mathrm{F})$ has been controllably discharged through the inductor. The control of the discharge time and the pulsed current allowed controlling the process of pressing (i.e. applied energy) for precise formation of the joint. The pressing has been performed using radial pressing of the thin-walled tubular sheath (copper tube) on the co-axial junction of the microcomposite conductors. The induction of the pulsed magnetic field inside the inductor for magnetic pressing triggered fast deformation (up to 100 $\mathrm{m} / \mathrm{s}$ ) of the copper tube around the conductors, which allowed forming a strong and tight connection of two conductors.

The schematic of the inductor for magnetic pressing technology and the sample positioning is shown in Fig. 2.

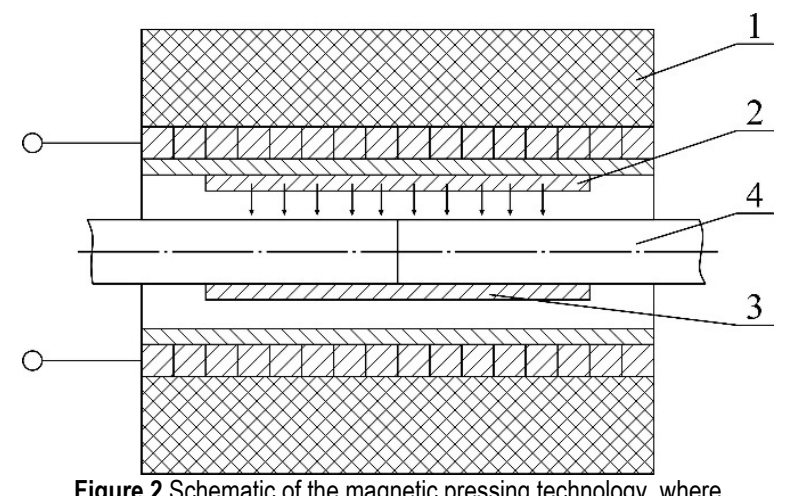

Figure 2 Schematic of the magnetic pressing technology, where

1 - inductor; 2 - tubular sheath for pressing; 3 - tubular sheath after pressing; 4 conductors, which are being connected
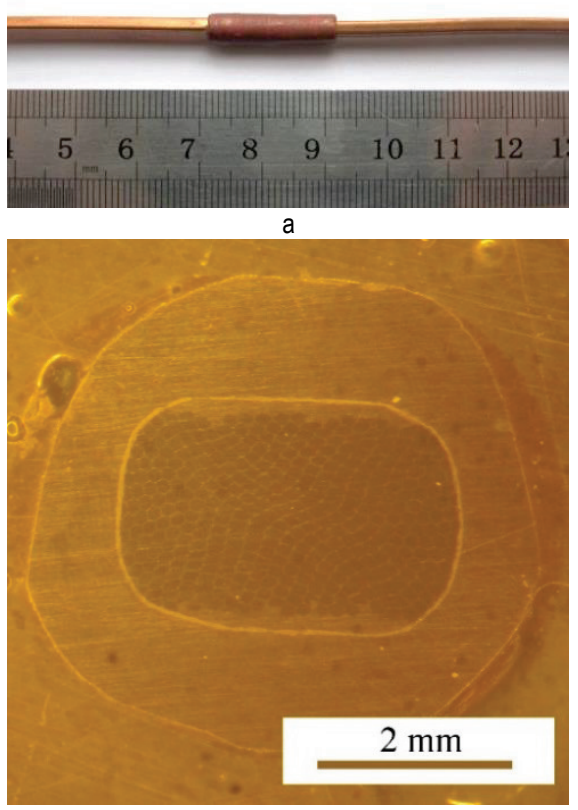

b

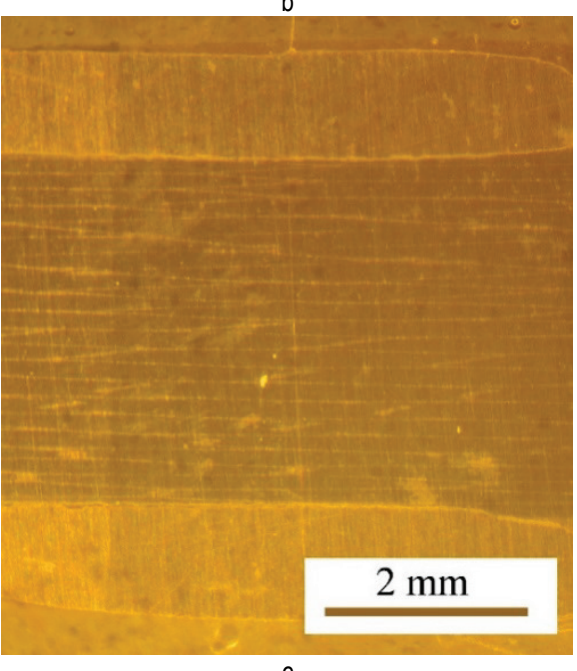

Figure 3 General view of the $\mathrm{Cu}-\mathrm{Nb}$ joint formed by pulsed magnetic field pressing: a - front view, $b$ - cross-section of joint; $c$ - longitudinal section of joint

The electrical characteristics of the resultant joint have been evaluated using U2810D Digital LCR Meter (China). 
The Joule heating in the joint has been evaluated experimentally using a current source (VDU-305) and termovisor (Flir E49001). The thermal distribution in the sample has been measured every $30 \mathrm{~s}$. The mechanical characteristics of the joint have been evaluated using tensile tests. A computerized setup with an analog-todigital converter Spider-8, Katman-Express software, dinamometer up to $20 \mathrm{kN}$ (accuracy $0,5 \%$ ) and a universal tensile testing machine TIRAtest 2300 have been applied. The microstructure of the joint formed by magnetic pressing technology has been analyzed both in longitudinal and transverse cross-sections. The surface was etched in $\mathrm{FeCl} 3 / \mathrm{HCl} / \mathrm{H} 2 \mathrm{O}$ solution and further analyzed using optical microscope Nikon Eclipse MA200 (Japan) and scanning electron microscopy (SEM) JEOL JSM-7600 (Japan).

\section{RESULTS AND DISCUSSION}

The general view of the $\mathrm{Cu}-\mathrm{Nb}$ joint formed by pulsed magnetic field pressing is shown in Fig. 3a. It can be seen in the longitudinal and transverse cross-sections of the joint (Figs. $3 \mathrm{~b}$ and $\mathrm{c}$ ) that the $\mathrm{Cu}$ tube was pressed to the surface $\mathrm{Cu}-\mathrm{Nb}$ wire, while the contact is uniform across the whole conductor in the joint section.

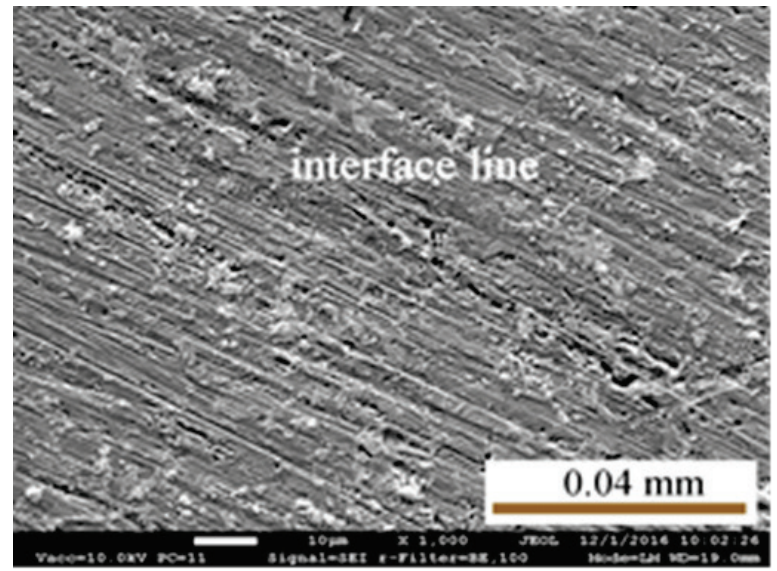

Figure 4 The joint interface between $\mathrm{Cu}-\mathrm{Nb}$ microcomposite and $\mathrm{Cu}$ sheath

The contact area has been further analysed using SEM microscopy and the photograph accurately representing the generality of observation is shown in Fig. 4. It can be seen that the contact area (Fig. 4, interface line) is barely distinguishable, which further supports the optical microscopy observations. Alternatively, the electrical conductivity of the joint has been compared to the same $\mathrm{Cu}-\mathrm{Nb}$ conductor wire of identical length, which was 0,01 $\Omega$ for the joint and $0,009 \Omega$ for the wire. The ratio of electrical conductivity (coefficient of defect) did not exceed 1,5 , which is in agreement with the requirements applicable for the electrical contact connections [15]. Nevertheless, the difference in the active resistance influenced the Joule heating. The thermal distribution after 2 min of 200 A current flow is shown in Fig. 5. The maximum difference in temperatures was up to $54,4{ }^{\circ} \mathrm{C}$, which is in agreement with the requirements applicable for the electrical contact connections [15].

The results of the joint transverse tensile test are presented in Fig. 6. The tensile strength of the $\mathrm{Cu}-\mathrm{Nb}$ joint was $351 \mathrm{MPa}$, elongation - 1,025\%. The acquired strength is $30,4 \%$ compared to the $\mathrm{Cu}-\mathrm{Nb}$ wire $(100 \%)$.

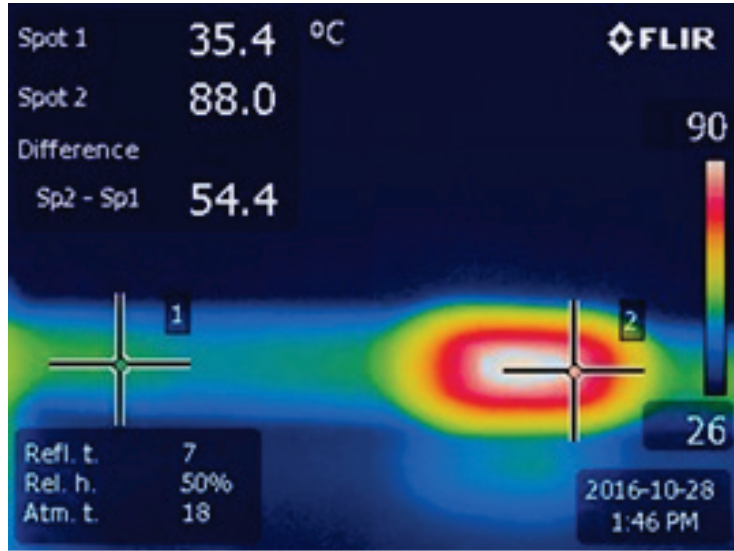

Figure 5 Thermal distribution after 2 min of 200 A current flow

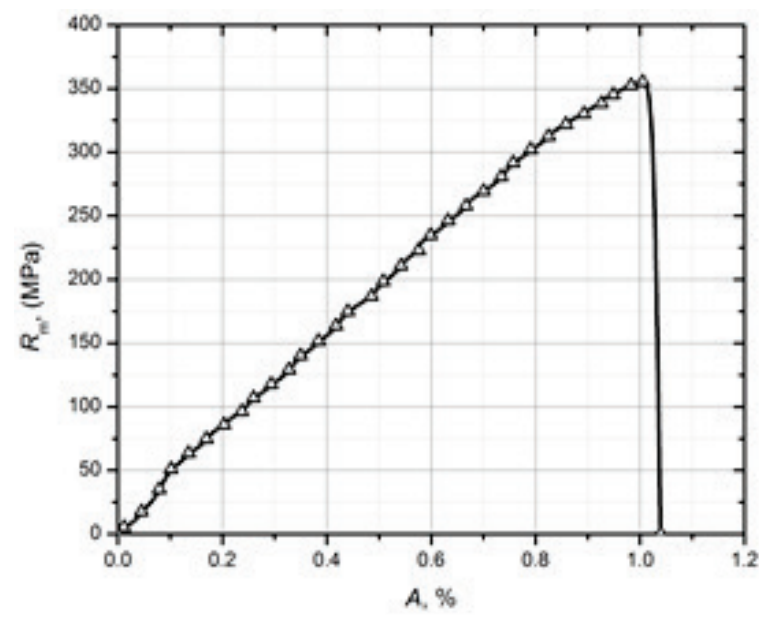

Figure 6 Stress-strain curve from a tensile test of welded joint: break point welding joint area

\section{CONCLUSION}

We have investigated the mechanical and electrical characteristics of $\mathrm{Cu}-\mathrm{Nb}$ joints formed by magnetic field pressing technology. It has been determined that the maximum tensile strength of $351 \mathrm{MPa}$ could be achieved (relative elongation of $1,025 \%$ ), which is $30,4 \%$ of a $\mathrm{Cu}-$ $\mathrm{Nb}$ wire. The acquired mechanical characteristics are comparable with soldered joints, however, up to $470 \mathrm{MPa}$ with $0,71 \%$ elongation could be achieved using the resistance welding joint forming technology [9]. Nevertheless, the magnetic field pressing technology has its own advantages, i.e. the joints are formed in solid state, which results in minimization of the number of defects in the structure of the microcomposite. Subsequently, the acquired electrical characteristics of the joint were satisfactory. It has been concluded that the acquired mechanical characteristics of $\mathrm{Cu}-\mathrm{Nb}$ joints are sufficient for forming of the pulsed power inductor terminals and interconnection with other power facilities. However, the application of the investigated method for interconnection of winding inside the inductor is still limited and requires further research and optimization. 


\section{Acknowledgements}

The authors team is grateful for all effort and support from Physical Technical Institute (National Academy of Sciences of Belarus) particularly Mr. Valerij Golubev for collaboration, joining samples preparation and consulting.

\section{REFERENCES}

[1] Herlach, F. \& Miura, N. (2003). High Magnetic Fields. Magnet Technology and Experimental Techniques. Science and Technology. Vol. 1. London, Imperial College Press. https://doi.org/10.1142/4764-vol1

[2] Shneerson, G. A., Dolotenko, M. I., \& Krivosheev, S. I. (2006). Strong and Superstrong Pulsed Magnetic Fields Generation. De Gruyter Studies in Mathematical Physics, 147-178.

[3] Han, K., Embury, J. D., Sims, J. R., Campbell, L. J, Schneider-Muntau, H. J., Pantsyrnyi, V. I., Shikov, A., Nikitin, A., \& Vorobieva, A. (1999). The Fabrication, Properties and Microstructure of $\mathrm{Cu}-\mathrm{Ag}$ and $\mathrm{Cu}-\mathrm{Nb}$ Composite Conductors. Material Science and Engineering, 267, 99-114. https://doi.org/10.1016/S0921-5093(99)00025-8

[4] Brandao, L., Han, K., Embury, J. D., Walsh, R., Toplosky, V., \& Van Sciver, S. (2000). Development of high strength pure cooper wires by cryogenic deformation for magnet application. IEEE Transaction of Applied Superconductivity, 10(1), 1282-1287. https://doi.org/10.1109/77.828470

[5] Shikov, A. K., Pantsyrnyi, V., Vorobeva, A., Sudev, S., Khlebova, N., Silajev, A., \& Belyakov, N. (2002). Copperniobium high strength and high conductivity winding wires for pulsed magnets. Material science and Heat Treatment, 44(11-12), 491-495. https://doi.org/10.1023/A:1022504805662

[6] Blumber, L., Hasizume, H., Ito, S., Minervini, J., \& Yanagi, N. (2010). Status of high temperature superconducting magnet development. RSFC/JA-10-45 report, pp. 3

[7] Jones, H., Van Cleemput, M., Hickman, A. L., Ryan, D. T., \& Saleh, P. M. (1998). Progress in High-Field Pulsed Magnets and Conductor Development in Oxford. Physica B, 246, 337-340. https://doi.org/10.1016/S0921-4526(97)00929-0

[8] Ciazynski, D., Duchateau, J., Decool, P., Libeyre, P., \& Turck, B. (2001). Large superconductors and joints for fusion magnets. From conceptual design to testing at full scale. IAEA Nuclear fusion, 41(2), 223-226. https://doi.org/10.1088/0029-5515/41/2/309

[9] Višniakov, N., Novickij, J., Ščekaturovienè, D., \& Petrauskas, A. (2011). Quality Analysis of Welded and Soldered Joints of $\mathrm{Cu}-\mathrm{Nb}$ Microcomposite Wires. Materials Science, 17(1), 16-19. https://doi.org/10.5755/j01.ms.17.1.242

[10] Yeo, H. K. \& Han, K. H. (2009). Wetting and spreading of molten $\mathrm{SnPb}$ solder on a $\mathrm{Cu}-10 \% \mathrm{Nb}$ micro-composite. Journal of Alloys and Compounds, 477(1-2), 278-282. https://doi.org/10.1016/j.jallcom.2008.10.150

[11] Rdzawski Z., Gluchovski W., Stobrawa J., Kempinski W., \& Andrzejewski B. (2015). Microstructure and properties of $\mathrm{Cu}-\mathrm{Nb}$ and $\mathrm{Cu}-\mathrm{Ag}$ nanofiber composites. Archives of civil and mechanical engineering, 15, 689-697. https://doi.org/10.1016/j.acme.2014.12.002

[12] Głuchowski, W., Stobrawa, J. P., Rdzawski, Z. M., \& Marszowski, K. (2011). Microstructural characterization of high strength high conductivity $\mathrm{Cu}-\mathrm{Nb}$ microcomposite wires. Journal of Achievements in Materials and Manufacturing Engineering, 46(1), 40-49.

[13] Messler, R. W. Jr. (2004). Principles of Welding: Processes, Physics, Chemistry, and Metallurgy, Wiley-VCH Verlag $\mathrm{GmbH}$, Weinheim.
[14] Višniakov, N., Novickij, J., Ščekaturovienė, D., \& Šukšta, M. (2006). Mechanical Properties of Winding Conductors Affected by Cyclic Thermal Overloads. Solid State Phenomena, 113, 541-544. https://doi.org/ 10.4028/www.scientific.net/SSP.113.541

[15] GOST 17441-84. Electrical contact connections. Acceptance rules and methods of tests, Euro-Asian Council for Standardization, Moscow, 1984.

\section{Contact information:}

Nikolaj VIŠNIAKOV, Dr.

Vilnius Gediminas Technical University

Faculty of Mechanics

Welding Research and Diagnostics Laboratory

Basanavičiaus str. 28, LT-03227, Vilnius, Lithuania

E-mail: nikolaj.visniakov@vgtu.It

Gediminas MIKALAUSKAS, PhD student

Vilnius Gediminas Technical University

Faculty of Mechanics

Department of Material Science and Welding

Basanaviciiaus str. 28, LT-03227, Vilnius, Lithuania

E-mail: gediminas.mikalauskas@vgtu.It

Raimonda LUKAUSKAITÉ, Dr.

Vilnius Gediminas Technical University

Faculty of Mechanics

Welding Research and Diagnostics Laboratory

Basanavičiaus str. 28, LT-03227, Vilnius, Lithuania

E-mail: raimonda.lukauskaite@vgtu.It

Jelena ŠKAMAT, Dr.

Vilnius Gediminas Technical University

Institute of Thermal Insulation

Linkmenu str. 28, LT-08217, Vilnius, Lithuania

E-mail: jelena.skamat@vgtu.lt

Olegas ČERNAŠĖJUS, Dr.

Vilnius Gediminas Technical University

Faculty of Mechanics

Department of Material Science and Welding

Basanavičiaus str. 28, LT-03227, Vilnius, Lithuania

E-mail: olegas.cernasejus@vgtu.lt

Vitalij NOVICKIJ, Dr.

Vilnius Gediminas Technical University

Faculty of Electronics

Institute of High Magnetic Fields

Naugarduko str. 41, LT-03227, Vilnius, Lithuania

E-mail: vitalij.novickij@vgtu.It 